7. "Sweet Potato." Encyclopedia of Food and Culture. Encyclopedia.com.. 2018, Мау 5. Електронний ресурс: http://www.encyclopedia.com.

8. Кужиль Н.О., Миколів Т.I. Перспективи використання батату у виробництві продуктів оздоровчого призначення // Міжнародна наукова конференція, присвячена 130-річчю Національного університету харчових технологій «Нові ідеї в харчовій науці нові продукти харчовій промисловості» 13-17 жовтня 2014 року. - Київ: НУХТ. - 2014. - С.50.

9. Petrova Zh.O., Slobodianiuk K.S. Energy effective drying modes of soy-vegetable compositions // Ukrainian Journal of Food Science. - 2017. - Volume 5, Issue 1. - P. 150 - 160

\title{
References
}

1. Ilchuk M.M., Konoval I.A., Kolos Z.V.. (2014) Vyrobnytstvo soi v Ukraini ta yoho resursne zabezpechennia na perspektyvu. Bioresursy i pryrodokorystuvannia. 6(12), 131-137.

2. Sniezhkin Yu.F., Petrova Zh.O. (2007) Teplomasoobminni protsesy pid chas oderzhannia karotynovmisnykh poroshkiv. Kyiv: VD «Akademperiodyka», 162.

3. Matti J. Tikkanen, Kristiina Wähälä, Sirpa Ojala, Veera Vihma, Herman Adlercreutz (1998) Effect of soybean phytoestrogen intake on low density lipoprotein oxidation resistance. Proceedings of the National Academy of Sciences of the United States of America, Mar 17 1998, 95(6). 3106-3110.

4. Hanzenko V.V. (2006) Soievi boby. Vplyv sposobu, stupenia yikh podribnennia i termoobrobky na tekhnolohichni vlastyvosti vodianykh suspenzii. Kharchova i pererobna promyslovist. 10, $24-25$.

5. Iukalo V. H., Melnichuk O. Ye., Selskyi V. R. (2014) Doslidzhennia khimichnoho skladu sortiv batatu, yaki vyroshchuiut v Ukraini. Naukovyi visnyk Poltavskoho universytetu ekonomiky i torhivli. 1 (70).68-72.

6. PinchukM.O. (2010) Batat - ekzotychnyi ovoch. Parostok. 1 (65). 21- 24.

7. (2018) "Sweet Potato." Encyclopedia of Food and Culture. Encyclopedia.com. http://www.encyclopedia.com.

8. Kuzhyl N.O., Mykoliv T.I. (2014) Perspektyvy vykorystannia batatu u vyrobnytstvi produktiv ozdorovchoho pryznachennia. Mizhnarodna naukova konferentsiia, prysviachena 130-richchiu Natsionalnoho universytetu kharchovykh tekhnolohii «Novi idei $v$ kharchovii nautsi - novi produkty kharchovii promyslovosti» 13-17 zhovtnia 2014 roku. Kyiv: NUKhT, 50.

9. Petrova Zh.O., Slobodianiuk K.S. (2017) Energy effective drying modes of soy-vegetable compositions. Ukrainian Journal of Food Science. 5(1),150-160.

Отримано в редакцію 11.05 .2018

Прийнято до друку 24.06.2018
Received 11.05.2018

Approved 24.06.2018

\section{ВПЛИВ ГІДРОДИНАМІЧНОЇ КАВІТАЩІї НА ЗМІНУ ТЕМПЕРАТУРНИХ ПОКАЗНИКІВ ВОДИ}

\author{
Авдсєва Л.Ю. Д-р техн. наук, с.н.с., Жукотський Е.К., Макаренко А.А. \\ Інститут технічної теплофізики НАН України, м. Київ
}

\begin{abstract}
Анотація. В статті розглянуті питання, пов'язані із виникненням і розвитком явища гідродинамічної кавітації при обробиі рідких середовищ. Показана актуальність і можливості практичного використання ефектів, що супроводжують гідродинамічну кавітацію, для інтенсифікації енергоємних процесів у різних галузях промисловості. Проаналізовано механізм інтенсифікуючого впливу дії ефектів кавітації в тепломасообмінних процесах. Описано переваги використання гідродинамічних кавітаторів статичногго типу на прикладі сопла Вентурі. Наведено результати експериментальних досліджень впливу ефектів гідродинамічної кавітації в соплі Вентурі на зміну температурних показників водопровідної води для визначення раціональних гідродинамічних умов проведення процесу обробки. Представлено дані, що характеризують зміни температурних показніків водопровідної води з різною початковою температурою в залежності від тривалості проведення прочесу для сопел з різним діаметром горловини. Показано, щуо збільшення тривалості обробки посилює вплив кавітаційних ефектів на матеріал. Встановлено, щио зменшення діаметру горловини сопла призводить до підвищення температури зразка в результаті його обробки. Найбільші кавітаџійні ефекти виникають при діаметрі горловини сопла Вентурі 0,008 м і 0,012 м. Встановлення діафрагми, що перекриває потік на 75\% показало додаткове загальне підвищення температури на 3-6 ${ }^{\circ}$, порівняно до отриманих результатів для зразка обробленого в кавітаційному змішувачі без діафрагми. Підвищення температури за рахунок встановлення діафрагми пояснюється посиленням дї кумулятивних ефектів внаслідок гідродинамічної кавітаційної обробки. Аналіз результатів експериментальних досліджень дозволив отримати математичну залежність числа кавітації від швидкості зміни температури за якою можна оцінити ефективність роботи кавітаційного змімувача.
\end{abstract}

Ключові слова: гідродинамічна кавітація, інтенсифікація масообмінних процесів, гідродинамічний змішувач статичного типу, сопло Вентурі 


\title{
THE EFFECT OF HYDRODYNAMIC CAVITATION FOR THE CHANGE OF WATER TEMPERATURE INDICATORS
}

\author{
Lesya Yu. Avdieieva, Eduard K. Zhukotskyi, Andrii A. Makarenko \\ Institute of Engineering Thermophysics of the National Academy of Sciences of Ukraine, Kyiv
}

\begin{abstract}
The article deals with issues related to the emergence and development of the phenomenon of hydrodynamic cavitation in the processing of liquid media. The actuality and possibilities of practical use of the effects accompanying hydrodynamic cavitation for the intensification of energy-intensive processes in various industries are shown. The mechanism of intensifying influence of cavitation effects in heat and mass transfer processes is analyzed. The advantages of static type hydrodynamic cavitators using the Venturi nozzle example are described. The results of experimental studies of the influence of the effects of hydrodynamic cavitation in the Venturi nozzle on the change of the temperature indices of tap water for the determination of rational hydrodynamic conditions of the processing process are given.

The data describing changes in temperature indices of tap water with different initial temperature are presented, depending on the duration of the process for nozzles with different diameter of the neck. It is shown that increasing the duration of processing enhances the effect of cavitation effects on the material. It was established that the decrease of the diameter of the nozzle's neck leads to an increase in the sample temperature as a result of its treatment. The largest cavitation effects arise at a diameter of the neck of the Venturi nozzle $0,008 \mathrm{~m}$ and $0,012 \mathrm{~m}$.

The installation of an aperture overlapping the flow by $75 \%$ showed an additional total temperature increase of 3-6 ${ }^{\circ} \mathrm{C}$, as compared to the results obtained for a sample treated in a cavitation mixer without a diaphragm. The increase in temperature due to the installation of the diaphragm is due to an increase in the effect of cumulative effects due to hydrodynamic cavitation treatment.

The analysis of the results of experimental studies allowed to obtain mathematical dependence of the number of cavitation on the rate of change in temperature on which it is possible to estimate the efficiency of the cavitation mixer.
\end{abstract}

Keywords: hydrodynamic cavitation, intensification of mass transfer processes, static hydrodynamic mixer, Venturi nozzle

Вступ. Гідродинамічна кавітація є явищем, яке відомо і вивчається вже досить давно. Останнім часом це пов'язано з можливістю інтенсифікації різноманітних енергоємних процесів і зменшенням питомих витрат енергії на виробництво продукції для різних галузей. 3 іiі допомогою можна створювати широкий спектр динамічного та термічного впливу, від м'якого до надзвичайно жорсткого, який дозволяє подолати високий рівень міжмолекулярних та внутрішньо молекулярних енергетичних зв'язків в складних гетерогенних дисперсних системах. На сьогодні кавітаційні технології є актуальними для енергетики, машинобудування, будівельної, хімічної, харчової промисловості де вони використовуються для змішування і перемішування рідких речовин які важко змішуються, розчинення твердих речовин, отримання високодисперсних емульсій без застосування стабілізаторів, диспергування суспензій і ін.

Аналіз проблематики та літературних джерел. Ефективність використання гідродинамічної кавітації пов'язана з виникненням супутніх ефектів, таких як ударні хвилі, випромінювання звукових імпульсів, кумуляція, автоколивання, вібротурбулізація, дифузія і теплообмін, які викликають зміну властивостей оброблюваних дисперсних систем. Теплообмінні процеси, які характерні для явища кавітації проявляються в т.ч. зміною температурних показників в кавітаційній зоні за рахунок утворення, зростання і колапсу бульбашок. При зхлопуванні, парогазова суміш, що міститься в бульбашці, стискається до тиску $10^{5}$ Па (300 атм) і нагрівається до температур порядку декілька тисяч градусів (8000-12000 К). При колапсі кожної бульбашки виникають імпульси тиску, які можуть досягати $10^{3}$ МПа. Весь процес збільшення і закриття бульбашок відбувається протягом декількох мілісекунд [4,5].

Незважаючи на велику кількість теоретичних і експериментальних досліджень фізична сутність i механізми впливу гідродинамічної вивчені ще недостатньо повно. Ряд питань, що стосуються впливу ефектів гідродинамічної кавітації, зокрема на зміну властивостей оброблюваних середовищ залишаються до теперішнього часу маловивченими. Це пов'язано з багатофакторністю впливу і досить значними відмінностями гідродинаміки потоку в апаратах різних конструкцій $[2,4,5,6]$.

Основою великої кількості відомих проточних кавітаційних апаратів статичного типу є сопла Вентурі, які мають суттєві переваги перед іншими типами кавітаторів. [6, 7, 8]. Це інтенсифікація проходження тепломасообмінних процесів, забезпечення безперервності технологічного процесу, висока якість обробки, а також простота та надійність обладнання. Важливим є розвиток кавітаційних ефектів в цьому типі апаратів за межами поверхні робочих органів, що $є$ основною проблемою виникнення кавітаційної ерозії $[1,3,4]$.

Кавітаційний реактор таких апаратів представляє собою послідовно поєднані між собою вхідний патрубок, конфузор, проточну камеру, дифузор і вихідний патрубок. На виникнення і розвиток кавітації 
впливають як гідродинамічні характеристики змішувача: форма меж течії, параметри течії (абсолютний тиск і швидкість), критичний тиск $\mathrm{P}_{\text {кав}}$, а також властивості матеріалу: вміст повітря, газу або твердих частинок, поверхневий натяг, в'язкість та ін. За зміною поведінки води, яка є дисперсійним середовищем для більшості харчових дисперсних систем, можна свідчити про основні закономірності кавітаційного впливу на дисперсну систему. [ 7,8].

Метою роботи було дослідження впливу особливостей конструкції сопла кавітаційного змішувача на зміну температурних показників водопровідної води для визначення раціональних умов проведення процесу диспергування. Вплив виникнення кавітаційних явищ в насосах був виключений попередніми експериментами, які показали незначне збільшення температури при роботі апарату без сопел, приблизно на $0,9-1,2{ }^{\circ} \mathrm{C}$.

Експериментальні дослідження. Обговорення рузультатів. Для досліджень був використаний кавітаційний апарат статичного типу зі змінними соплами. Були використані сопла діаметром горловини від 0,004 м, 0,008 м, 0,012 м і 0,016 м при тому ж куті розкриття конфузору і куті розкриття дифузору. Результати досліджень наведені на рис. 1 .

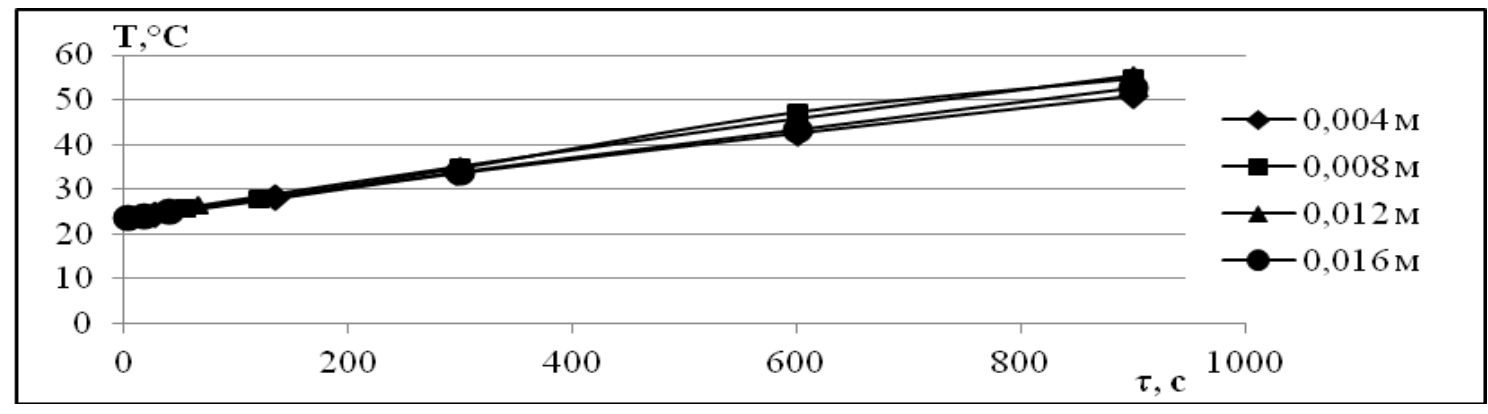

\section{Рис.1 Залежність зміни температури від тривалості кавітаційної обробки}

Наведені результати досліджень (рис.1) дозволили охарактеризувати зміни температурних показників водопровідної води в залежності від тривалості проведення процесу для сопел з різним діаметром горловини. Було підтверджено, збільшення тривалості обробки призводить до поступового підвищення температури для всій дослідних зразків.

Під впливом виникнення кавітаційних явищ в результаті проведення кавітаційної обробки впродовж 15 хв. для всіх дослідних зразків водопровідної води температура зросла 3 початкової 23-25 ${ }^{\circ} \mathrm{C}$ до 51 $56{ }^{\circ} \mathrm{C}$, тобто на $28-31{ }^{\circ} \mathrm{C}$. Швидкість зростання становила приблизно $1,7{ }^{\circ} \mathrm{C} /$ хв. Найбільше зростання температурних показників спостерігалося при використанні в конструкції апарату сопел 3 діаметрами 0,008 м і 0,012 м, додатково на $3-5^{\circ} \mathrm{C}$.

Отримані результати дозволили встановити залежність зміни температури від початкової до кінцевої $(\Delta \mathrm{T})$ зразків водопровідної води від внутрішнього діаметру горловини сопла (рис. 2).

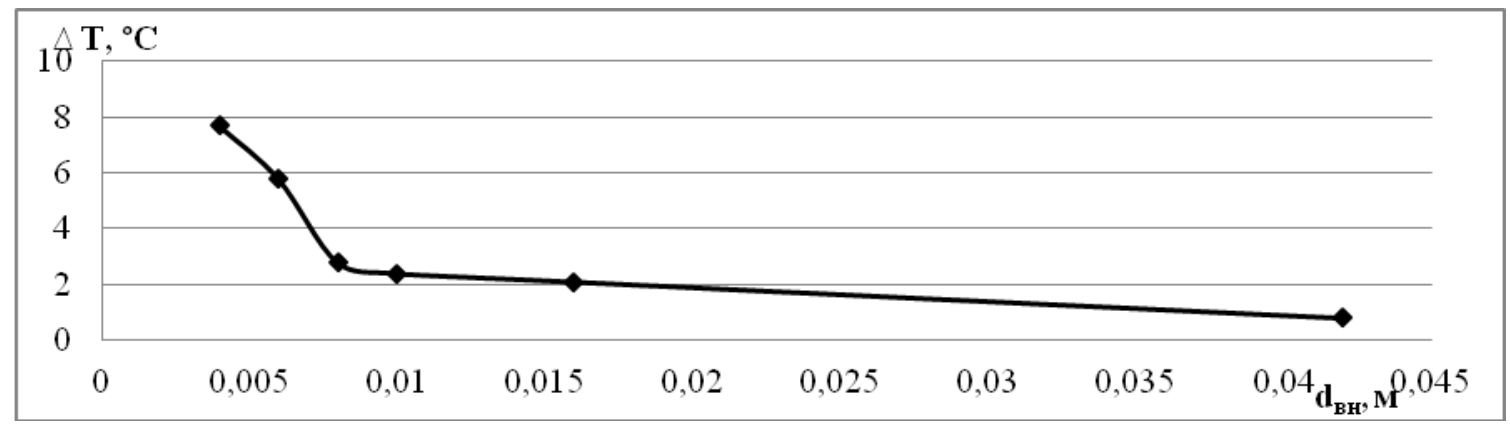

Рис.2 Залежність зміни температури від внутрішнього діаметру кавітатора.

Отримана залежність (рис. 2) дозволила показати, що при зменшенні діаметру горловини сопла відбувається підвищення температури обробленого зразку. Це може свідчити про посилення кавітаційного впливу на матеріал. Найменші зміни одержаних показників характерні для зразка обробленого в апараті без сопла, внутрішній діаметр труби становить 0,042 м, що підтверджує зроблені висновки.

Нами було досліджено вплив підвищення температури зразків водопровідної води при кавітаційний обробці при збільшенні початкових температур. При виконанні досліджень було використано сопло 3 діаметром горловини 0,008 м. Результати наведені на рис.3. 


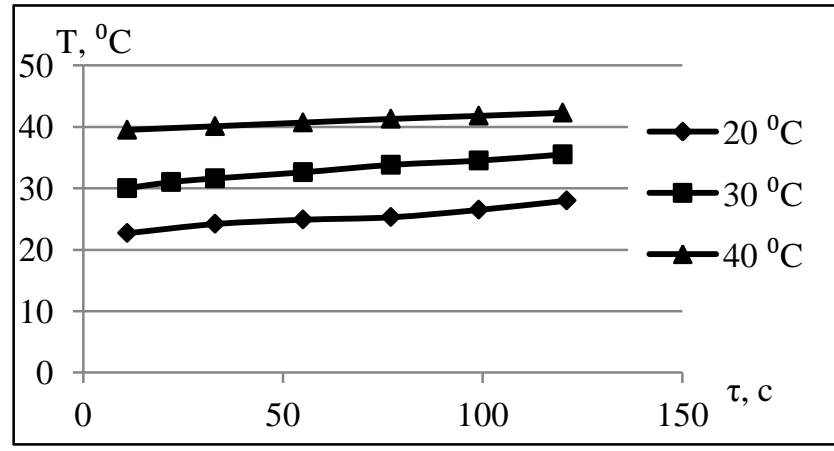

a)

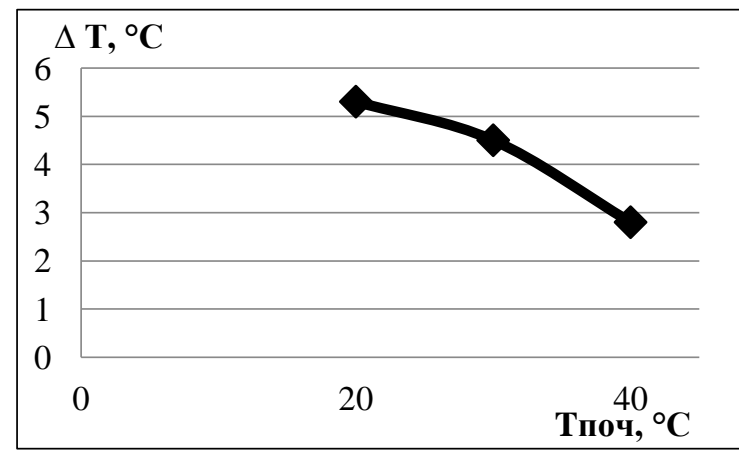

б)

а - залежність початкової температури від тривалості обробки;

б - залежність зміни температури в процесі обробки від початкової температури

Рис. 3. Вплив початкових температур зразків водопровідної води на зростання температури в результаті кавітаційної обробки:

Дослідження показали, що підвищення початкової температури призводить до уповільнення зростання кінцевої температури (рис3 а). Так, в результаті обробки впродовж 120 с при початковій температурі зразків $20 \pm 2{ }^{\circ} \mathrm{C}$ і $30 \pm 2^{\circ} \mathrm{C}$ температура підвищилась на 5,3-5,5 $\mathrm{C}$, але збільшення початкової температури до $40 \pm 2^{\circ} \mathrm{C}$ призводить до підвищення температури матеріалу до $3{ }^{\circ} \mathrm{C}$. Спостерігається майже зворотна пропорційна залежність між показниками $\Delta \mathrm{T}$ і T (рис.3 б). Збільшення тривалості обробки призводить до посилення цих залежностей. Отримані результати можуть свідчити про зменшення інтенсивності кавітаційного впливу через зменшення кількості газоповітряних включень у воді в результаті її попереднього нагрівання.

Були проведені дослідження по визначенню впливу кавітаційної обробки на температурні показники матеріалу при послідовному встановленні в потоці за соплом Вентурі додаткового опору у вигляді діафрагми з різною площею перекриття перерізу: 25\%, 50\% і 75\%. Максимальна зміна температур була досягнута при використанні діафрагми, що перекриває площу потоку на 75\%. Результати досліджень визначення температурних показників при обробці зразків водопровідної води впродовж 11 циклів (66 с) в кавітаційному змішувачі з горловиною сопла 0,012 м 3 встановленою діафрагмою, що перекриває потік на $75 \%$ і без неї наведені на рис. 4 .

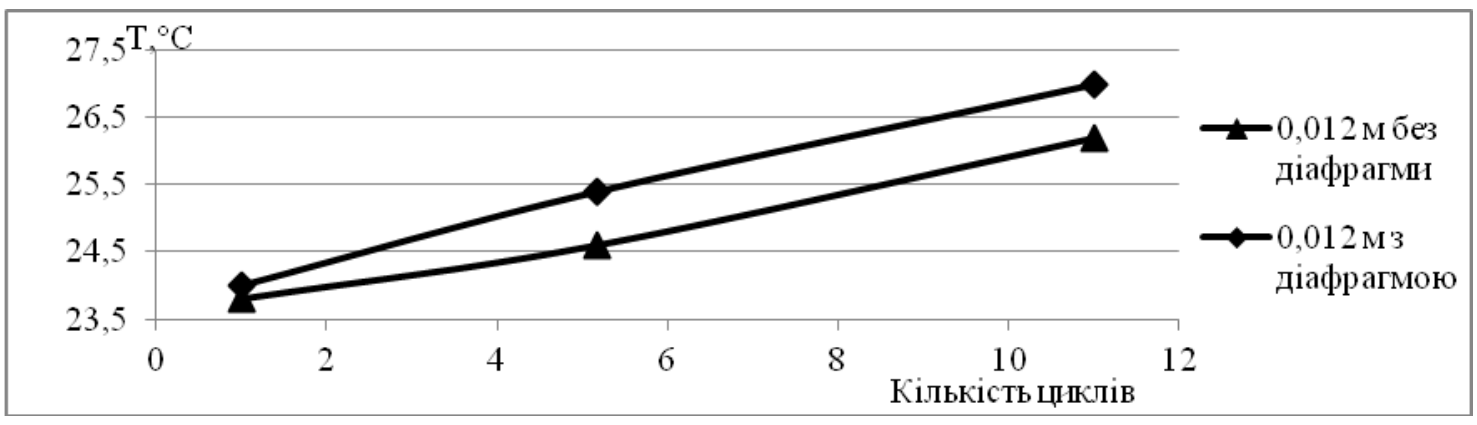

Рис.4. Залежність температурних показників від кількості циклів кавітаційної обробки.

Наведені залежності (рис. 4) показали, що встановлення діафрагми призводить до додаткового підвищення температури дослідного зразка при його обробці впродовж 11 циклів (66 с) майже на $1^{\circ} \mathrm{C}$, що свідчить про посилення дії кумулятивних ефектів гідродинамічної кавітації. В результаті збільшення тривалості обробки до 15 хв. температура зразка, обробленого в кавітаційному апараті з встановленою діафрагмою підвищилась 3 початкової 22-23 ${ }^{\circ} \mathrm{C}$ до 55-60 ${ }^{\circ} \mathrm{C}$ - майже на 33 - $37{ }^{\circ} \mathrm{C}$. Це на 3-6 ${ }^{\circ} \mathrm{C}$ більше, порівняно до зразка обробленого в апараті без діафрагми. Одержані результати дозволяють зробити висновок про те, що використання в конструкції апарату дифузору у вигляді шайби із різною площею перекриття потоку призводить до додаткової турбулізації потоку і створення вихрових зон з великою дисипацією енергії. Це призводить до посилення дії кавітаційних ефектів на матеріал.

Отримані результати підтверджують висновки результатів попередніх досліджень щодо впливу ефектів гідродинамічної кавітації на електрохімічні властивості води при використанні сопла 3 діаметром 0,012 м і діафрагми, що перекриває потік на 75\% [7].

Проведені дослідження дозволили пов'язати гідродинамічні умови проведення процесу і число кавітації із швидкістю зміни температури матеріалу. На рис. 5 наведено математичну залежність числа кавітації від швидкості зміни температури. 


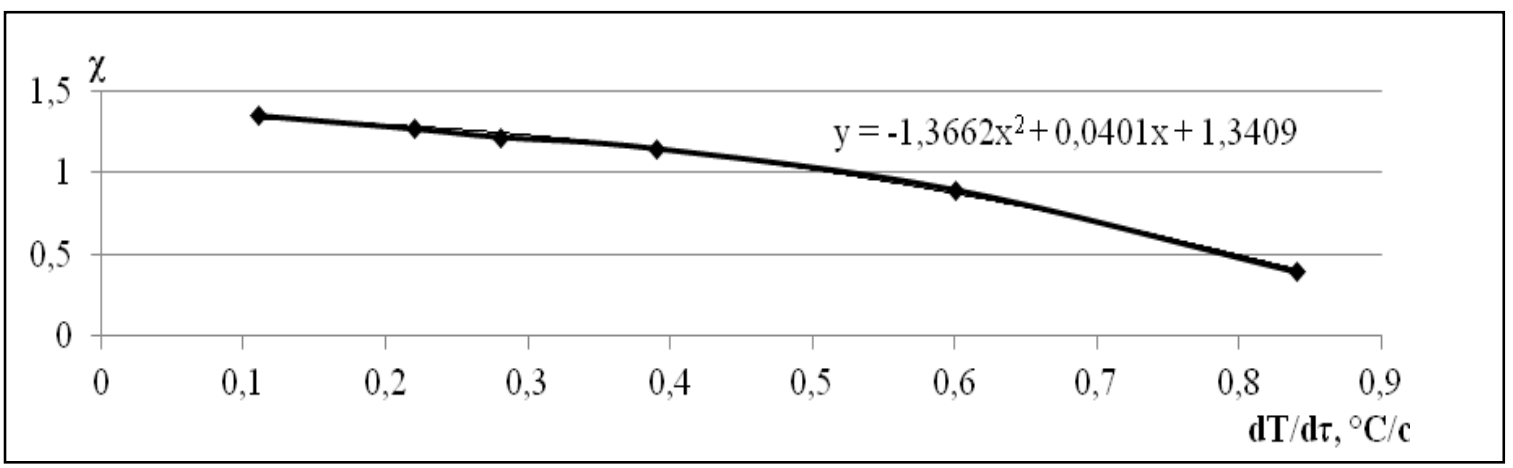

Рис. 5. Залежність числа кавітації від швидкості зміни температури.

Отримана математична залежність (рис.5) дозволяє оцінити ефективність роботи кавітаційного змішувача за швидкістю зміни температури матеріалу.

\section{Висновки.}

Застосування кавітаційних технологій дозволяє інтенсифікувати і знизити енерговитратність багатьох масообмінних і гідромеханічних процесів у різних галузях. Гідродинамічні умови проведення кавітаційної обробки, а саме характеристики змішувача: форма меж течії, параметри течії (абсолютний тиск і швидкість), критичний тиск $\mathrm{P}_{\text {кав}}$, а також властивості матеріалу мають суттєвий вплив на розвиток кавітаційних ефектів. Проведені експериментальні дослідження впливу параметрів сопла кавітаційного змішувча на водопровідну воду показали, що зменшення діаметру горловини сопла призводить до підвищення температури обробленого зразку. Підвищення початкової температури призводить до уповільнення зростання кінцевої температури зразка в результаті обробки. Найбільші кавітаційні ефекти виникають при діаметрі горловини сопла 0,008 м і 0,012 м. Встановлення діафрагми призводить до додаткового підвищення температури дослідного зразка. Це може свідчити про посилення кавітаційного впливу на матеріал. Комплекс проведених досліджень дозволив визначити конструктивні параметри проточних кавітаційних змішувачів для створення раціональних умов проведення процесу диспрегування. Аналіз результатів експериментальних досліджень дозволив отримати залежність числа кавітації від швидкості зміни температури. Отримана залежність дозволяє оцінювати ефективність роботи кавітаційного змішувача.

\section{Література}

1. Перник А.Д. Проблемы кавитации / А.Д. Перник.- М., Судостроение, 1966. - 439 с.

2. Gogate P. A A review and assessment of hydrodynamic cavitation as a technology for the future/ P.R. Gogate, A.B. Pandit Ultrasonics Sonochemistry - 2005. - №12. - P. 21-27.

3. Young F.R. Cavitation/ London, U.K. : Imperial College Press, 1999. - 418 p.

4. Braeutigam P. Role of Different Parameters in the Optimization of Hydrodynamic Cavitation/ P. Braeutigam, M. Franke, Zhi-Lin Wu, B. Ondruschka - Chem. Eng. Technol. - 2010,33. - No. 6 - P. 932-940.

5. Вітенько Т.М. Гідродинамічна кавітація у масообмінних, хімічних і біологічних процесах/ Т.М.Вітенько. - Тернопіль: ТДТУ ім.І.Пулюя, 2009. - 220 с.

6. Федоткин И.М., Гулый И.С. Кавитация, кавитационная техника и технология, их использование в промышленности (теоретические основа производства, расчеты и конструкция кавитационных теплогенераторов) Часть II. Киев: АО «ОКО», 2000.898 с.

7. Кавітаційний змішувач-реактор для обробки суспензій та отримання колоїдних систем: пат. 90264 Україна: МПК(2014.01) В01F 5/00, B01F 3/04 (2006.01) № u 201308931; заявл. 16.07.2013; опубл. 26.05.2014, бюл. № 11 .

8. Multi-chamber supercavitation reactor: pat. US 2007/0189114 A1 USA, Int. Cl. B01F 5/08, B01J 19/26. № 11/679,665, 27.02.2007; Pub, date 16.08.2007

9. Долінський А.А. Використання кавітаційних технологій при обробці рідких гетерогенних систем /Долінський А.А., Авдєєва Л.Ю., Жукотський Э.К., Макаренко А.А.// Наукові праці ОНАХТ, 2014.- вип. 45, Т. 3.-С. 9-13.

10. Авдєєва Л.Ю. Вплив ефектів гідродинамічної кавітації на електрохімічні властивості води /Авдєєва Л.Ю., Макаренко А.А. // Наукові праці ОНАХТ, 2017, Т.81.-№1.-С. 105-110.

\section{Referenses}

1. Pernyk A.D. (1966) Problemi kavytatsyy. Moskva: Sudostroenye,. 439.

2. Gogate P.R., Pandit A.B. (2005) A review and assessment of hydrodynamic cavitation as a technology for the future. Ultrasonics Sonochemistry, 12, 21-27.

3. Young F.R. (1999) Cavitation. London: Imperial College Press, 418

4. Braeutigam P., Franke M., Zhi-Lin Wu, Ondruschka B. (2010) Role of Different Parameters in the Optimization of Hydrodynamic Cavitation. Chem. Eng. Technol., 6, 932-940.

5. Viten'ko T.M. (2009) Hidrodynamichna kavitatsiya u masoobminnykh, khimichnykh i biolohichnykh protsesakh. Ternopil': TDTU im.I.Pulyuya, 220.

6. Fedotkin I.M., Gulyiy I.S. Kavitatsiya, (2000) kavitatsionnaya tehnika i tehnologiya, ih ispolzovanie v promyishlennosti (teoreticheskie osnova proizvodstva, raschetyi i konstruktsiya kavitatsionnyih teplogeneratorov) Chast II. Kiev: AO «OKO», 898.

7. KavItatsIyniy zmIshuvach-reaktor dlya obrobki suspenzIy ta otrimannya koloYidnih sistem: pat. 90264 UkraYina: MPK(2014.01) B01F 5/00, B01F 3/04 (2006.01) \# u 201308931; zayavl. 16.07.2013; opubl. 26.05.2014, byul. \# 11.

8. Multi-chamber supercavitation reactor: pat. US 2007/0189114 A1 USA, Int. Cl. B01F 5/08, B01J 19/26. № 11/679,665, 27.02.2007; Pub, date 16.08.2007

9. Dolynskyy A.A., Avdeeva L.YU., Zhukotskiy E.K., Makarenko A.A (2014) Vykorystannya kavitatsiynykh tekhnolohiy pry obrobtsi ridkykh heterohennykh system. Scientific Works, Odesa. 45, 2. P.9-13

Наукові праці, Том 82, випуск 1 Scientific Works, Volume 82, Issue 1 
10. Avdeeva L.YU., Makarenko A.A (2017) Vplyv efektiv hidrodynamichnoyi kavitatsiyi na elektrokhimichni vlastyvosti vody. Scientific Works, Odesa. 81, 1. P.105-110

Отримано в редакцію 11.05.2018

Прийнято до друку 24.06.2018
Received 11.05.2018

Approved 24.06.2018

\title{
ВПЛИВ ШВИДКОСТІ РУХУ ПОВІТРЯ НА ПРОЦЕС КОНВЕКТИВНО-ТЕРМОРАДІАЦІЙНОГО СУШІННЯ ЯБЛУЧНИХ СНЕКІВ
}

\author{
Малежик І. Ф., Д-р техн. наук, професор, Дубковецький І. В., канд. техн. наук., доцент, \\ Стрельченко Л. В., аспірант \\ Національний університет харчових технологій, м. Київ
}

\begin{abstract}
Анотація. В процесі розвитку технічного прогресу харчова промисловість вимагає нових технологічних рішень для підвищення якості харчових продуктів. Сегмент ринку снеків в наш час дуже поширений та популярний серед споживачів, проте якість цих снеків бажала б бути вищою, а асортимент різноманітнішим. Саме ия проблема наштовхнула нас на створення нового продукту з відмінними харчовими властивостями та збалансованим хімічним складом. Маючи базу попередніх досліджень оптимальних параметрів сушіння снеків, необхідно визначити вплив швидкісті руху повітря на прочес сушіння. Швидкість ичиркулящії повітря в сушильному пристрої - найважливіший параметр процесу сушіння. Чим вище швидкість цииркуляції, тим, за інших рівних умов, менша тривалість процесу, вища продуктивність сушіння, менша нерівномірність сушіння матеріалу, більші витрати електроенергії і в більшості випадків вища собівартість.

Нами запропоновано комбінувати два способи підведення теплоти при сушінні - терморадіаційний $i$ конвективний, щзо дозволило зменшити відносну вологість повітря $i$ збільшити рушійну силу процесу $в$ порівнянні з сушінням інфрачервоними променями. Для цьього була спроектована і виготовлена сушильна установка, яка дозволяє сушити терморадіаційним і конвективним способами як окремо, так $i$ їх поєднанням. В роботі викладені результати досліджень впливу швидкості ичиркуляції сушильного агента на основні параметрів процесу сушіння в радіаційно-конвективній установці періодичної дії. Механізм та інтенсивність перенесення вологи у матеріалі залежать від взаємопов'язаного комплексу процесів порушення зв'язку вологи з матеріалом та дифузї парогазового середовища через капілярно-порову структуру матеріалу. В даній роботі встановлені залежності основних тепломасообмінних характеристик конвективно-терморадіаційного сушіння яблучних снеків від швидкості руху повітря.
\end{abstract}

Ключові слова: снеки, бланшування, сировина, сушіння, швидкість повітря, температура, вологовміст.

\section{INFLUENCE OF AIR TRAFFIC SPEED ON THE PROCESS OF CONVECTIVE-THERMORADIATIVE DRYING OF APPEAL ANIMALS}

\author{
Malezhick I.F., Dr. Of Tech. Sci., prof., Dubkovetskiy I.V., PhD, Associate prof., \\ Strelchenko K.V., postgraduate student \\ National University of Food Technologies, Kyiv, Ukraine
}

\begin{abstract}
In the process of developing technical progress, the food industry requires new technological solutions to improve the quality of food products. The snack market segment is nowadays very popular and popular among consumers, but the quality of these snacks would be desirable, and the assortment is more diverse. This problem has led us to create a new product with excellent nutritional properties and a balanced chemical composition. Having a base of preliminary studies of the optimum parameters of drying snakes, it is necessary to determine the effect of the speed of air movement on the drying process. The rate of air circulation in the dryer is the most important parameter of the drying process. The higher the circulation velocity, the more equal conditions, the shorter the duration of the process, the higher the drying performance, the less uneven material drying, the greater the cost of electricity and in most cases the higher cost.

We are proposed to combine two methods of supplying heat during drying - thermal radiation and convection, which allowed to reduce the relative humidity of air and increase the motive force of the process compared with the drying of infrared rays. For this purpose, a drying plant was designed and manufactured, which allows drying by thermal radiating and convection methods both individually and in combination. The paper presents the results of studies on the influence of the circulation velocity of a drying agent on the main
\end{abstract}

